\title{
Diagnoses of Primary Cause of Mortality in Domestic Sheep in the North American Intermountain West
}

\author{
David J Wilson*, Thomas J Baldwin and E Jane Kelly \\ School of Veterinary Medicine, Department of Animal, Dairy and Veterinary Sciences, Utah State University, Logan, UT, USA
}

\begin{abstract}
Causes of death of 246 domestic sheep (Ovis aries) necropsied from 2009-2016 at the Utah Veterinary Diagnostic Laboratory were summarized. Sheep originated from Utah $(93 \%)$, Idaho $(6 \%)$ or Wyoming $(0.4 \%)$. There were 54 fetuses, 214 week lambs (1-28 d old), 69 young lambs (29-180 d), 28 older lambs (181-365 d), and 74 adult sheep $(>365 \mathrm{~d})$. If no age was provided, age was estimated from body weight based on literature and expert opinion. Of the $45 \%$ of sheep with age provided, $90 \%$ matched with the body weight estimates. Primary cause of mortality was diagnosed in 228 cases (93\%); 6 diseases accounted for $136(60 \%)$ of the diagnoses: abortion $50(22 \%)$, parasitism 29 (13\%) (most from H. contortus), pneumonia $19(8 \%)$ (95\% bacterial), enteritis/enterotoxemia $17(7 \%)$, bloat $13(6 \%)$, and selenium deficiency $8(4 \%)$. No cause of death was evident in 18 sheep $(7 \%)$. The most common cause of fetal death was abortion 50 (93\%). In 4 week lambs, most common causes were 4 pneumonia (19\%), and 3 parasitism (14\%). In young lambs, 15 parasitism (22\%) (10 Haemonchus contortus), and 10 pneumonia (15\%) (9 bacterial pneumonia) predominated. In older lambs, 7 parasitism $(25 \%)(4 \mathrm{H}$. contortus, 3 Fasciola hepatica), 3 bacterial pneumonia (11\%) and 3 clostridial enterotoxemia (11\%) were most common. Most common causes of adult sheep death were 5 bloat $(7 \%), 4 \mathrm{H}$. contortus (5\%), 4 peritonitis $(5 \%), 4$ bacterial pneumonia $(5 \%)$, and 4 urolithiasis $(5 \%)$, a cause of death only found in adult sheep. Control measures for the most common causes of domestic sheep mortality include vaccination and clean lambing environment to reduce abortions, enterotoxemia and other infectious disease, control of parasite infestation, prevention and treatment of pneumonia and bloat, and adequate mineral supplementation.
\end{abstract}

Keywords: Sheep; Mortality; Pathology; Pathogens

\section{Introduction}

The Intermountain West region (Utah, Idaho, and Nevada, sometimes defined as including western Wyoming, northern Arizona, western Colorado, and northwestern New Mexico) has the greatest proportion of the 5.2 million domestic sheep in the United States [1]. Utah is the fifth-ranked state $(275,000$ sheep, $5.3 \%)$ and Idaho is seventh $(250,000,4.8 \%)$ [1]. According to data from 2012 (most recent data available) there were 1,755 sheep farms in Utah and 1,241 in Idaho [2]. Sheep are produced primarily for meat and secondarily for wool. Sheep industry sales totaled approximately $\$ 360$ million in the U.S. during 2016 [3]. The objective of this descriptive study was to identify and summarize the causes of mortality as diagnosed from postmortem examination of 246 sheep from the Intermountain West over a 7-year period.

\section{Materials and Methods}

Domestic sheep included in this descriptive case series were necropsied from January 2009 through April 2016 at the Utah Veterinary Diagnostic Laboratory (UVDL). Sheep submitted with advanced postmortem degradation were disposed of rather than necropsied. No age was provided for more than half of the necropsied sheep. Therefore, except for fetuses, age was estimated from body weight based on the literature and expert opinion. Definitions of age categories and body weights for each category other than fetuses: 4 week lamb 1-28 d old, $<8$ kg; young lamb 29-180 d old, 8-35 kg; older lamb 181-365 d old, 35.1 $54 \mathrm{~kg}$; adult $>365 \mathrm{~d},>54 \mathrm{~kg}$.

\section{Specimen collection}

Tissues and fluids routinely collected differed among fetuses and other age groups. From all fetuses, samples of liver, lung, kidney, spleen and abomasal fluid were collected and stored at $-20^{\circ} \mathrm{C}$. Also from all fetuses, lung, rumen, abomasum, liver, heart, kidney, spleen, thymus, adrenal glands, thyroid, brain and placenta (if submitted) were collected and placed in $10 \%$ neutral buffered formalin (NBF).

From all adults, samples of liver, lung, kidney, and spleen were collected and stored at $-20^{\circ} \mathrm{C}$. Samples of esophagus, trachea, lung, rumen, reticulum, omasum, abomasum, intestine (multiple levels), pancreas, liver, heart, kidney, skeletal muscle, urinary bladder, reproductive organs (ovaries, uterus, testes), lymph node, spleen, thymus (juveniles), adrenal glands, thyroid, and brain were collected and placed in NBF. Collection of additional tissues and/or organs depended on reported clinical signs and gross findings at postmortem examination. After fixation, tissues were subsampled, processed, sectioned, and stained by routine methods. Tissues stained with hematoxylin and eosin were examined microscopically. Special stained replicate sections, including tissue Gram stains, periodic acid-Schiff, and Masson's trichrome, were prepared and examined on a case-by-case basis.

\section{Ancillary tests}

Bacterial isolation was done by sampling tissues or body fluids and

*Corresponding author: David J Wilson, School of Veterinary Medicine Department of Animal, Dairy and Veterinary Sciences, Utah State University, 950 East 1400 North, Logan, UT 84341, USA, Tel: 4357603731; Fax: 4357972805; E-mail: David.Wilson@usu.edu

Received October 30, 2017; Accepted November 09, 2017; Published November 10,2017

Citation: Wilson DJ, Baldwin TJ, Kelly EJ (2017) Diagnoses of Primary Cause of Mortality in Domestic Sheep in the North American Intermountain West. J Vet Sci Technol 8: 487. doi: 10.4172/2157-7579.1000487

Copyright: $\odot 2017$ Wilson DJ, et al. This is an open-access article distributed under the terms of the Creative Commons Attribution License, which permits unrestricted use, distribution, and reproduction in any medium, provided the original author and source are credited. 
plating directly on trypticase soy agar with $5 \%$ sheep blood, chocolate blood agar, Columbia nutrient agar, and MacConkey agar (all agars from Hardy Diagnostics, Santa Maria, CA). Resulting colonies were identified to genus level using either API (bioMérieux Inc., Durham, NC) or BBL Crystal (Becton Dickenson and Co., Franklin Lakes, NJ) test kits. Parasitism was detected by fecal flotation and identification of oocytes; direct visualization of gastrointestinal parasites occurred occasionally (e.g., large numbers of grossly visible $H$. contortus). Copper and selenium were quantified using inductively coupled plasma-mass spectroscopy. Vitamin E testing was performed at the California Animal Health and Food Safety Laboratory System (Davis, California).

\section{Determination of cause of death}

Cause of death was established based on reported clinical signs, pathology, and results of ancillary tests. Where multiple diseases or conditions were diagnosed, death was attributed to the disease that caused the most pathology in critical organs and/or tissues.

\section{Electronic capture of data}

All diagnostic findings were entered into a laboratory information management system (Vetstar animal disease diagnostic system [VADDS], Advanced Technology Corp., Ramsey, NJ). The system recorded owner and animal data, postmortem examination and laboratory test results, and allowed for the composition of text to summarize case findings. Data was summarized by review of diagnostic reports and entered into data fields using a commercial spreadsheet (Excel, Microsoft Corp., Redmond, WA). The following data fields were populated: accession number, state of origin, age (estimated from body weight if not provided), weight, breed, sex, diagnosis of cause of death, and agent isolated (where applicable). Totals by category were calculated.

\section{Results}

Postmortem examinations were performed on 246 domestic sheep during the 7-year period of study. Sheep were presented in groups of 1 to 7 animals with a mean of 1.2 animals per submission (there were 209 submissions). The sheep originated from farming operations or range flocks in Utah-229 sheep (93\%) from 199 submissions, Idaho-16 sheep (6\%) from 9 submissions, or Wyoming-1 sheep (0.4\%) from one submission. No age was provided for 135 (55\%) of necropsied sheep. Of the 111 (45\%) sheep with an age provided, 100 (90\%) matched with the body weight-based estimates. The breed of most sheep was not reported and could not be determined $(174,71 \%)$, unless the sheep was a Suffolk because of that breed's distinctive appearance. Breeds identified were: Suffolk 45 (18\%), Rambouillet 9 (4\%), Hampshire 3 (1\%), other breeds (1-2 sheep per breed) 15 (6\%).

\section{Descriptive data by age group}

There were 54 fetuses, 214 week lambs, 69 young lambs, 28 older lambs, and 74 adult sheep. Descriptive data are shown in Table 1.

\section{Overall causes of sheep mortality}

Diagnosis of primary cause of mortality was made in 228 cases (93\%); no cause of death was evident in 18 sheep (7\%). Of the 228 sheep where cause of death were established, 6 diseases accounted for 136 (60\%) of the diagnoses: abortion 50 (22\%), parasitism 29 (13\%) $(66 \%$ of parasitism deaths were from $H$. contortus), pneumonia $19(8 \%)(95 \%$ were bacterial pneumonia), enteritis/enterotoxemia 17 (7\%), bloat 13 (6\%), and selenium deficiency 8 (4\%). Diagnoses of primary cause of death for all sheep are provided in Table 2 . Approximately two-thirds of deaths with a diagnosis $(145,64 \%)$ were attributed to infectious disease, while the remaining one-third $(83,36 \%)$ were noninfectious (Table 2).

\section{Causes of mortality in fetuses}

Of 54 fetuses submitted for necropsy, abortion (50 cases, 93\%) was the most common cause of death, and 4 (7\%) died from dystocia (Table 3 ). Bacterial abortion (other than chlamydial) was the most common cause among abortions, with 29 (54\%) cases. In 21 of those cases, bacteria were observed histopathologically, but microbiology was not performed. For 8 cases, a specific bacterial cause was determined: 3 Campylobacter jejuni, 2 Campylobacter fetus, 1 Escherichia coli, 1 Streptococcus sanguinius, and 1 Streptococcus dysgalactiae. There were 12 (22\%) idiopathic abortions, including 1 mummified fetus. The third most common cause of fetal death was abortion caused by Chlamydia abortus ( 8 cases, $15 \%)$ and there was 1 case (2\%) of nutritional myopathy from selenium deficiency.

\section{Causes of mortality in $\mathbf{4}$ week lambs}

Diagnoses of cause of mortality for 4 week lambs $(n=21)$ are shown in Table 4. The most common cause was pneumonia, with 4 cases (19\%), 2 caused by Mannheimia haemolytica, and 2 by aspiration. Three lambs (14\%) died from parasitism (coccidiosis, cryptosporidiosis and haemonchosis), and 3 cases (14\%) had no diagnosis. Dystocia ( 2 cases, $10 \%)$ was the next most common cause of death. There were 9 other diseases (43\%) with a single case of each: bacterial enteritis, esophagitis with rumenitis, omphalophlebitis, polioencephalomalacia, pulmonary congestion with edema, renal failure, rumenitis, selenium deficiency, and spider lamb syndrome (hereditary chondrodysplasia, including disproportionately long, spider like legs, and spinal curvature, often with other deformities) [4].

\section{Causes of mortality in young lambs}

Of 69 young lambs necropsied, 15 (22\%) died from parasitism $(67 \%$ H. contortus) and 10 (15\%) from pneumonia (90\% bacterial) (Table 5). Specific causes of pneumonia were $3 \mathrm{M}$. haemolytica, 2 Pseudomonas aeruginosa, 2 diagnosed as bacterial in origin but with no pathogens isolated at culture, 1 Pasteurella multocida, 1 Bibersteinia trehalosi, and

Table 1: Sex, age and weight data for 246 sheep necropsied from 2009-2016.

\begin{tabular}{|c|c|c|c|c|c|c|c|c|c|c|}
\hline Age Group & No. & M & $\mathbf{F}$ & $\begin{array}{l}\text { Sex } \\
\text { NR }^{\neq}\end{array}$ & $\begin{array}{l}\text { Age } \\
\text { Mean }\end{array}$ & $\begin{array}{c}\text { Age } \\
\text { Median }\end{array}$ & $\begin{array}{c}\text { Age } \\
\text { Range }\end{array}$ & $\begin{array}{l}\text { Weight } \\
\text { Mean }\end{array}$ & $\begin{array}{l}\text { Weight } \\
\text { Median }\end{array}$ & $\begin{array}{l}\text { Weight } \\
\text { Range }\end{array}$ \\
\hline Fetus & 54 & 29 & 11 & 14 & $N A^{*}$ & NA & NA & 3.2 & 3.2 & $0.3-7.3$ \\
\hline 4 Week Lamb & 21 & 9 & 9 & 3 & $12 \mathrm{~d}$ & $10 \mathrm{~d}$ & $1-28 d$ & 5.7 & 5.3 & $3.2-11.0$ \\
\hline Young Lamb & 69 & 35 & 32 & 2 & $121 \mathrm{~d}$ & $120 \mathrm{~d}$ & $32-180 \mathrm{~d}$ & 22.0 & 20.5 & $8.6-42.5$ \\
\hline Older Lamb & 28 & 15 & 11 & 2 & $309 d$ & $333 d$ & $210-365 d$ & 45.4 & 46.7 & $33.4-58.1$ \\
\hline Adult & 74 & 51 & 23 & 0 & $3.6 \mathrm{yr}$ & $3 \mathrm{yr}$ & $1-13 \mathrm{yr}$ & 80.3 & 75.7 & $33.0-150.0$ \\
\hline
\end{tabular}

\#: Sex not reported; £: Body weights in kg; ¥: Not applicable 
Citation: Wilson DJ, Baldwin TJ, Kelly EJ (2017) Diagnoses of Primary Cause of Mortality in Domestic Sheep in the North American Intermountain West. J Vet Sci Technol 8: 487. doi: 10.4172/2157-7579.1000487

Table 2: Diagnoses of cause of death in 246 domestic sheep.

\begin{tabular}{|c|c|}
\hline Disease or condition & No. affected ${ }^{*}$ \\
\hline Abortion & $50(20.3)$ \\
\hline Parasitism & $29(11.8)$ \\
\hline Pneumonia & $19(7.7)$ \\
\hline No diagnosis & $18(7.3)$ \\
\hline Enteritis/enterotoxemia & $17(6.9)$ \\
\hline Bloat & $13(5.3)$ \\
\hline Selenium deficiency & $8(3.3)$ \\
\hline Peritonitis & $7(2.8)$ \\
\hline Dystocia & $6(2.4)$ \\
\hline Polioencephalomalacia & $5(2.0)$ \\
\hline Lymphoma/Lymphosarcoma & $4(1.6)$ \\
\hline Pulmonary edema & $4(1.6)$ \\
\hline Septicemia & $4(1.6)$ \\
\hline Urolithiasis & $4(1.6)$ \\
\hline Copper toxicity & $3(1.2)$ \\
\hline Mastitis & $3(1.2)$ \\
\hline Metritis & $3(1.2)$ \\
\hline Abomasal impaction & $2(0.8)$ \\
\hline Abomasitis & $2(0.8)$ \\
\hline Copper deficiency & $2(0.8)$ \\
\hline Emaciation & $2(0.8)$ \\
\hline Encephalitis (listeriosis) & $2(0.8)$ \\
\hline Myocarditis & $2(0.8)$ \\
\hline Neonatal atelectasis & $2(0.8)$ \\
\hline Omphalophlebitis & $2(0.8)$ \\
\hline Plant toxicosis & $2(0.8)$ \\
\hline Pregnancy toxemia & $2(0.8)$ \\
\hline Pulmonary abscesses & $2(0.8)$ \\
\hline Rumen acidosis & $2(0.8)$ \\
\hline Rumenitis & $2(0.8)$ \\
\hline Acidophil adenoma & $1(0.4)$ \\
\hline Ascites & $1(0.4)$ \\
\hline Cecal and colonic impaction & $1(0.4)$ \\
\hline Esophageal choke & $1(0.4)$ \\
\hline Esophagitis & $1(0.4)$ \\
\hline Hepatotoxicity & $1(0.4)$ \\
\hline Hypomyelinogenesis & $1(0.4)$ \\
\hline $\begin{array}{l}\text { Jejunal entrapment and infarction (post- } \\
\text { surgical) }\end{array}$ & $1(0.4)$ \\
\hline Meningitis & $1(0.4)$ \\
\hline Myocardial degeneration & $1(0.4)$ \\
\hline Myodegeneration & $1(0.4)$ \\
\hline Pancreatitis & $1(0.4)$ \\
\hline Paravertebral abscess & $1(0.4)$ \\
\hline Pleuritis/pericarditis & $1(0.4)$ \\
\hline Pyelonephritis & $1(0.4)$ \\
\hline Pyrrolizidine alkaloid toxicity & $1(0.4)$ \\
\hline Rectal perforation & $1(0.4)$ \\
\hline Renal failure & $1(0.4)$ \\
\hline Retained placenta and metritis & $1(0.4)$ \\
\hline Spider lamb syndrome & $1(0.4)$ \\
\hline Starvation, hypothermia & $1(0.4)$ \\
\hline Trauma (subdural hematoma) & $1(0.4)$ \\
\hline Urethral squamous metaplasia & $1(0.4)$ \\
\hline Total & $246(100)$ \\
\hline
\end{tabular}

"Numbers in parentheses are percentages
Table 3: Causes of death in 54 fetal sheep.

\begin{tabular}{|c|c|}
\hline Disease or condition & ${\text { No. } \text { affected }^{*}}^{*}$ \\
\hline Abortion, bacterial (other than chlamydial) & $29(53.7)$ \\
\hline Abortion, idiopathic (1 mummified) & $12(22.2)$ \\
\hline Abortion, chlamydial & $8(14.8)$ \\
\hline Dystocia (3 with fluid and meconium in lungs) & $4(7.4)$ \\
\hline Abortion, nutritional myopathy & $1(1.9)$ \\
\hline
\end{tabular}

"Numbers in parentheses are percentages

Table 4: Causes of death in 21 four week lambs (1-28 d old).

\begin{tabular}{|c|c|}
\hline Disease or condition & ${\text { No. } \text { affected }^{*}}^{*}$ \\
\hline Pneumonia (2 $M$. haemolytica, 2 aspiration) & $4(19.0)$ \\
\hline Parasitism & $3(14.3)$ \\
\hline No diagnosis & $3(14.3)$ \\
\hline Dystocia (born alive, died soon after) & $2(9.5)$ \\
\hline $\begin{array}{c}\text { Other (9 diseases, a single case of each; see } \\
\text { text) }\end{array}$ & $9(42.9)$ \\
\hline
\end{tabular}

"Numbers in parentheses are percentages

Table 5: Causes of death in 69 young lambs (29- $180 \mathrm{~d}$ old $)$

\begin{tabular}{|c|c|}
\hline Disease or condition & No. affected" \\
\hline Parasitism (10 H. contortus) & $15(21.7)$ \\
\hline Pneumonia (9 bacterial, 1 aspiration) & $10(14.5)$ \\
\hline Enteritis & $7(10.1)$ \\
\hline Bloat (5 frothy) & $6(8.7)$ \\
\hline $\begin{array}{l}\text { Peritonitis (all with perforated abomasal } \\
\text { ulcers) }\end{array}$ & $3(4.3)$ \\
\hline Selenium deficiency & $3(4.3)$ \\
\hline $\begin{array}{c}\text { Septicemia (castration, tail dock, unknown } \\
\text { origin) }\end{array}$ & $3(4.3)$ \\
\hline No diagnosis & $3(4.3)$ \\
\hline Abomasitis & $2(2.9)$ \\
\hline Clostridial enterotoxemia & $2(2.9)$ \\
\hline Polioencephalomalacia & $2(2.9)$ \\
\hline $\begin{array}{l}\text { Other (13 diseases, a single case of each; } \\
\text { see text) }\end{array}$ & $13(18.8)$ \\
\hline
\end{tabular}

Numbers in parentheses are percentages

1 aspiration. Next most common causes of death were 7 enteritis cases $(10 \%)$ and 6 bloat (9\%) (83\% frothy bloat). There were $3(4 \%)$ cases of peritonitis secondary to perforated abomasal ulcers, $3(4 \%)$ cases of selenium deficiency, $3(4 \%)$ cases of septicemia including 2 that were sequellae of surgery, and 3 cases (4\%) with no diagnosis. Other causes of death included 2 abomasitis (3\%), 2 clostridial enterotoxemia (3\%), and 2 polioencephalomalacia (3\%). There were 13 other diseases (19\%) with a single case of each: ascites, copper deficiency, encephalitis (listeriosis), hypomyelinogenesis, myocarditis, myodegeneration, omphalophlebitis, paravertebral abscess, pericarditis, pulmonary abscesses, rumenitis, suppurative meningitis and urethral squamous metaplasia.

\section{Causes of mortality in older lambs}

The most common causes of mortality for older lambs $(n=28)$ were 7 cases of parasitism $(25 \% ; 57 \%$ H. contortus, $43 \%$ F. hepatica), bacterial pneumonia 3 (11\%), and clostridial enterotoxemia 3 (11\%) (Table 6). Specific causes of pneumonia were P. multocida, Streptococcus bovis and aspiration, and Trueperella pyogenes. Next most common were 2 cases (7\%) of frothy bloat, 2 (7\%) of plant toxicosis, 2 (7\%) of selenium deficiency, and 2 cases (7\%) had no diagnosis. Other causes of death included single cases of 7 (25\%) diseases: copper toxicity, enteritis, jejunal entrapment and infarction (post-surgical), lymphosarcoma 
Table 6: Causes of death in 28 older lambs (181 - $365 \mathrm{~d}$ old).

\begin{tabular}{|c|c|}
\hline Disease or condition & ${\text { No. } \text { affected }^{*}}^{*}$ \\
\hline Parasitism (4 H. contortus, 3 F. hepatica) & $7(25.0)$ \\
\hline Pneumonia (all bacterial) & $3(10.7)$ \\
\hline Clostridial enterotoxemia & $3(10.7)$ \\
\hline Bloat, frothy & $2(7.1)$ \\
\hline Plant toxicosis & $2(7.1)$ \\
\hline Selenium deficiency & $2(7.1)$ \\
\hline No diagnosis & $2(7.1)$ \\
\hline Other (7 diseases, a single case of each; \\
see text)
\end{tabular}

${ }^{*}$ Numbers in parentheses are percentages

Table 7: Principal causes of death in 74 adult (1-13 yr old) sheep

\begin{tabular}{|c|c|}
\hline Disease or condition & No. affected $^{*}$ \\
\hline No diagnosis & $10(13.5)$ \\
\hline Bloat (3 gas, 1 abomasal, 1 frothy) & $5(6.8)$ \\
\hline Parasitism (all H. contortus) & $4(5.4)$ \\
\hline Peritonitis (1 post-surgical dehiscence) & $4(5.4)$ \\
\hline Pneumonia (all bacterial) & $4(5.4)$ \\
\hline Urolithiasis & $4(5.4)$ \\
\hline Clostridial enterotoxemia & $3(4.1)$ \\
\hline Mastitis & $3(4.1)$ \\
\hline Metritis & $3(4.1)$ \\
\hline Pulmonary edema & $3(4.1)$ \\
\hline Abomasal impaction & $2(2.7)$ \\
\hline Copper toxicity & $2(2.7)$ \\
\hline Emaciation & $2(2.7)$ \\
\hline Lymphosarcoma & $2(2.7)$ \\
\hline Polioencephalomalacia & $2(2.7)$ \\
\hline Selenium deficiency & $2(2.7)$ \\
\hline Other (19 diseases, a single case of & $19(25.7)$ \\
\hline each; see text) & \\
\hline
\end{tabular}

"Numbers in parentheses are percentages

with spinal cord involvement, pregnancy toxemia, retained placenta with metritis, and rumen acidosis.

\section{Causes of mortality in adult sheep}

Of 74 adult sheep necropsied, the most common causes of death were $5(7 \%)$ bloat cases, $4(5 \%) H$. contortus infestation, 4 (5\%) peritonitis, 4 (5\%) bacterial pneumonia, and $4(5 \%)$ urolithiasis, a cause of death only found in adult sheep (Table 7). Specific causes of pneumonia were M. haemolytica, $P$. multocida, and T. pyogenes (the remaining case was not cultured due to tissue autolysis). Next most common causes of death were 3 (4\%) clostridial enterotoxemia, 3 (4\%) mastitis which only caused death in adult sheep, 3 (4\%) metritis, 3 (4\%) pulmonary edema, 2 (3\%) abomasal impaction, 2 (3\%) copper toxicity, 2 (3\%) emaciation (no clear underlying cause), 2 (3\%) lymphosarcoma, 2 (3\%) polioencephalomalacia and $2(3 \%)$ selenium deficiency. There were 19 other diseases (26\%) with a single case of each: pituitary (acidophil) adenoma, cecal and colonic impaction, copper deficiency, encephalitis (listeriosis), esophageal choke, hepatotoxicity, lymphoma (tracheal pressure at thoracic inlet), myocardial degeneration, myocarditis, pancreatitis, pregnancy toxemia, pulmonary abscesses, pyelonephritis, pyrrolizidine alkaloid toxicity, rectal perforation, rumen acidosis, septicemia, starvation, and trauma with subdural hematoma. Ten (14\%) adult sheep had no diagnosis of cause of death.

\section{Discussion}

As expected, most common causes of mortality observed in domestic sheep varied with age. In fetuses, over $90 \%$ of deaths were abortions and bacterial infection was detected in more than half of these, most commonly Chlamydia abortus followed by Campylobacter jejuni and Campylobacter fetus when a specific pathogen was identified. However, most abortions where bacteria were observed histologically were not cultured because despite being in sufficient preservation for necropsy, bacterial overgrowth or contamination was considered likely because of the condition of the tissues. These agents reported here have often been described in this order as the most common causes of ovine abortion worldwide, including the U.S., even though most of the data comes from the United Kingdom or elsewhere [5,6]. No summary reports of diagnostic results of causes of ovine abortion in the U.S. have been published for over 20 years, when C. fetus was isolated more frequently than C. jejuni and C. abortus [7]. No diagnosis could be made in one-fifth of the fetuses in the present study, including one that was mummified, while in the 1993 report, $56 \%$ of abortions, $6 \%$ of which were mummified, could not be diagnosed [7]. Other results in this report are similar to the 1993 findings.

A variety of parasitic, infectious, and metabolic diseases caused death in lambs during the first month of life. Spider lamb syndrome and parasitism have been previously described $[4,8]$, but there are no refereed publications summarizing causes of lamb deaths during the first month of life in North America.

Lambs from 1 to 6 months old died primarily from $H$. contortus infestation, bacterial pneumonia, enteritis, and frothy bloat. These diseases have been reported as major causes of sheep losses, but not specifically by age [9-12].

Six-months to 1-year-old lambs died of similar causes to the above age group, but nearly half of the deaths from parasites were attributed to liver flukes (F. hepatica). The pre-patent period for this parasite is at least 3 months, which partly accounts for why it was not observed at necropsy in younger animals. Fascioliasis is recognized as an important cause of sheep mortality and its prevalence is increasing in many parts of the world in association with warmer temperatures $[12,13]$.

Adult sheep exhibited the greatest variety of fatal diseases. Some were similar to those that killed younger sheep such as parasitism, pneumonia and bloat. However, causes of adult mortality also included obstructive urolithiasis, mastitis, metritis, neoplasia and trauma. Urolithiasis, mastitis, and metritis are recognized as important and common diseases in sheep, including as causes of mortality $[6,14,15]$. One sheep had a pituitary acidophil adenoma while another had pancreatitis. The only previous report of acidophil adenoma in a sheep was in an adult ewe being treated experimentally with reproductive hormones [16]. Pancreatitis was reported at necropsy of sheep in 1960 and suggested to be associated with chronic copper toxicity, but the mechanism or origin of pancreatitis in sheep was not definitively identified [17].

This observational study is a report of diagnoses of mortality in domestic sheep from a partly state-funded laboratory. A potential limitation of the study is that in a diagnostic service for clientele, primarily livestock owners or submitting veterinarians, this setting does not always allow for complete, exhaustive diagnostic procedures. Financial considerations often preclude additional testing (e.g., PCR, virus isolation, toxicological testing, etc.) outside of routine necropsy procedures. Nevertheless, these results reflect diagnoses of the main 
Citation: Wilson DJ, Baldwin TJ, Kelly EJ (2017) Diagnoses of Primary Cause of Mortality in Domestic Sheep in the North American Intermountain West. J Vet Sci Technol 8: 487. doi: 10.4172/2157-7579.1000487

causes of death in farmed or range flock sheep presented for necropsy from the Intermountain West region of the U.S.

Control measures for the most common causes of domestic sheep mortality include vaccination and clean lambing environment to reduce infectious abortions and enterotoxemia, control of parasite infestation including $H$. contortus and $F$. hepatica, prevention and treatment of bloat, pneumonia, mastitis and metritis, and adequate mineral supplementation, particularly copper and selenium levels and prevention of urolithiasis [18].

\section{Acknowledgments}

We thank the sheep producers, veterinarians, and other clients of the UVDL who submitted the sheep for necropsy. Operational support for the diagnostic laboratory is provided by the Utah Department of Agriculture and Food.

\section{References}

1. Beef 2 Live (2017) Top 10 States with the Most Sheep \& Lambs.

2. USDA (2012) National Agricultural Statistics Service, Statistics by State.

3. USDA (2017) National Agricultural Statistics Service, Agricultural Statistics Board. Sheep and Lamb Inventory Down 2 Percent.

4. Beever J, Smit M, Meyers S, Hadfield T, Bottema C, et al. (2006) A single-base change in the tyrosine kinase II domain of ovine FGFR3 causes hereditary chondrodysplasia in sheep. Anim Genet 37: 66-71.

5. Longbottom D, Entrican G, Wheelhouse N, Brough H, Milne C (2013) Evaluation of the impact and control of enzootic abortion of ewes. Vet J 195: 257-259.

6. Sanad Y, Jung K, Kashoma I, Zhang X, Kassem I, et al. (2014) Insights into potential pathogenesis mechanisms associated with Campylobacter jejuniinduced abortion in ewes. BMC Vet Res 10: 274-278.
7. Kirkbride C (1993) Diagnoses in 1,784 ovine abortions and stillbirths. J Vet Diagn Invest 5: 398-402.

8. Notter D, Burke J, Miller J, Morgan J (2017) Factors affecting fecal egg counts in periparturient Katahdin ewes and their lambs. J Anim Sci 95: 103-112.

9. Tomassini L, Gonzales B, Weiser G, Sischo W (2009) An ecologic study comparing distribution of Pasteurella trehalosi and Mannheimia haemolytica between Sierra Nevada bighorn sheep, White Mountain bighorn sheep, and domestic sheep. J Wildl Dis 45: 930-940.

10. Villalba J, Provenza F, Stott R (2009) Rumen distension and contraction influence feed preference by sheep. J Anim Sci 87: 340-350.

11. Paddock R (2011) Haemonchus contortus in sheep and goats: An insidious killer. Indiana Animal Disease Diagnostic Laboratory Fall 2011 Newsletter.

12. Taylor M (2012) Emerging parasitic diseases of sheep. Vet Parasitol 189: 2-7.

13. Rojo-Vázquez F, Meana A, Valcárcel F, Martínez-Valladares M (2012) Update on trematode infections in sheep. Vet Parasitol 189: 15-38.

14. Jones M, Gibbons P, Roussel A, Dominguez B (2017) Mineral composition of uroliths obtained from sheep and goats with obstructive urolithiasis. J Vet Intern Med 31: 1202-1208.

15. Martins K, Faccioli P, Bonesso M, Fernandes S, Oliveira A et al. (2017) Characteristics of resistance and virulence factors in different species of coagulase-negative staphylococci isolated from milk of healthy sheep and animals with subclinical mastitis. J Dairy Sci 100: 2184-2195.

16. Olson D, Ohlson D, Davis S, Laurence K (1981) Acidophil adenoma in the pituitary gland of a sheep. Vet Pathol 18: 132-135.

17. Monlux W, Johnson M, Preston K (1960) Chronic copper poisoning and pancreatitis in sheep. lowa St Univ Vet 22: Article 7.

18. Schoenian S (2017) Maryland Small Ruminant Page, Health and Diseases. 